\title{
Aprender a língua espanhola pelo aplicativo Vecindario: soluções para as necessidades contemporâneas
}

\author{
Izabel Rego de Andrade', Ricardo Caceffo², Renan Paes Souza ${ }^{2}$, Rodolfo Azevedo², \\ Denise Braga $^{1}$
}

${ }^{1}$ Instituto de Estudos da Linguagem - Universidade Estadual de Campinas, UNICAMP - Campinas, SP - Brazil.

${ }^{2}$ Instituto de Computação - Universidade Estadual de Campinas, UNICAMP Campinas, SP - Brazil.

izarego@gmail.com, caceffo@ic.unicamp.br, renan-plsouza@uol.com.br, rodolfo@ic.unicamp.br,denisebbraga@gmail.com

\begin{abstract}
Resumo. Este artigo descreve o protótipo do aplicativo móvel Vecindario, dedicado à aprendizagem de espanhol como língua estrangeira por estudantes universitários brasileiros. Considerar os contextos de uso da língua pelos aprendizes, a sua língua materna, bem como as suas necessidades de aprendizagem estão entre os diferenciais pedagógicos desse aplicativo projetado para o sistema operacional Android.
\end{abstract}

\section{Cenário de uso}

Os aplicativos móveis (APPs) desenvolvidos atualmente para estudo auto monitorado de línguas estrangeiras consideram conceitos de língua vinculados a metodologias estruturalistas e a recortes da língua-alvo que não vão além de tópicos do vocabulário e gramática. O uso de metodologias tão antigas como, por exemplo, a behaviorista, restringe as possibilidades de aprendizagem de línguas estrangeiras a estruturas linguísticas rígidas e limitadas, pouco contribuindo para o desenvolvimento da autonomia do aprendiz em relação à língua estudada.

Após uma análise técnica e pedagógica de aplicativos disponíveis no mercado, foi projetado um aplicativo para aprendizagem de língua estrangeira, ajustado às necessidades de aprendizagem do jovem brasileiro de hoje em dia. O aplicativo Vecindario foi elaborado considerando uma educação linguística contemporânea, tendo como público alvo estudantes universitários brasileiros e propondo o estudo da língua espanhola.

\section{Desenvolvimento}

O currículo dos conteúdos tratados no aplicativo considerou aquilo que um aprendiz brasileiro, com pouco conhecimento prévio na língua espanhola, seria capaz de adquirir dentro dos níveis iniciais de proficiência. Após a seleção do currículo, foi elaborado um mapa de atividades que foi utilizado posteriormente para a roteirização das telas em 
VI Congresso Brasileiro de Informática na Educação (CBIE 2017)

Anais dos Workshops do VI Congresso Brasileiro de Informática na Educação (WCBIE 2017)

forma de storyboard, com 83 telas que descrevem tecnica e pedagogicamente todo o conteúdo e as interações previstas no uso do aplicativo.

O protótipo do aplicativo móvel Vecindario foi produzido utilizando o software Android Studio. Algumas bibliotecas do Android foram utilizadas para implementar integrações com Facebook (2017), Youtube (2017) e Whatsapp (2017). Cada tela do aplicativo é constituída de dois arquivos: um arquivo XML, responsável pela parte gráfica (como a visualização de textos, botões, imagens e menus); e um arquivo Java, responsável pela parte lógica. $\mathrm{O}$ arquivo Java responde às interações feitas pelo usuário na tela, incluindo a transição entre telas através do movimento sensível ao toque. $\mathrm{O}$ código fonte é gerado em um arquivo XML (Android Manifest) com informações essenciais sobre o aplicativo, como o nome do pacote Java, as permissões que o aplicativo possui, a versão mínima da API que ele pode ser executado, além dos nomes de todos os arquivos Java utilizados.

Cada nova versão do aplicativo foi armazenada em um repositório, facilitando a manutenção, a organização e a atualização do aplicativo, além de permitir que todos os membros do projeto pudessem desenvolver uma mesma versão desde os seus computadores locais. No projeto, foi utilizado o controlador de versões Git (2017), um sistema livre e de código aberto, com a função de guardar o histórico de alterações de arquivos, permitindo assim a coordenação do trabalho entre várias pessoas.

Com o intuito de tornar mais simples a aplicação e a interação com o Git, foram usados os sistemas Bitbucket (2017) e SourceTree (2017). O Bitbucket é um repositório (em nuvem ou cloud) Git para times de desenvolvimento de software, ou seja, ele apresenta de forma simples e confiável funcionalidades de armazenamento de dados em Git. Com esse modelo, os desenvolvedores do projeto puderam trabalhar em paralelo no processo de codificação. Os sistemas utilizados gerenciaram o controle de versões e, em alguns casos específicos, até mesmo conflitos de desenvolvimento (merges) causados pela alteração de um mesmo arquivo, ao mesmo tempo, por mais de um desenvolvedor. Esse procedimento garantiu a integridade do processo de codificação.

Para validar o protótipo foi realizado um teste piloto com alunos de diferentes cursos da Unicamp que aceitaram ser voluntários no processo de avaliação do aplicativo, totalizando 8 alunos voluntários. Após o recebimento de uma mensagem por e-mail, o voluntário interessado deveria acessar o site indicado, com informações de esclarecimento e termo de consentimento, antes de iniciar a sua participação (VECINDARIO, 2017a). Primeiramente o candidato deveria escolher se preferiria participar do grupo 1 (on-line) ou do grupo 2 (presencial). A seguir, deveria responder a um questionário on-line que visava averiguar sua experiência prévia ou não com uso de telefones celulares para aprender línguas estrangeiras. Caso o usuário escolhesse a forma on-line, após responder o questionário, deveria instalar o aplicativo no seu celular e iniciar o seu uso. Após cerca de 10 dias, era agendada uma entrevista por telefone para levantar dados referentes à sua experiência (pesquisa de opinião). Caso escolhesse o grupo 2, deveria agendar data e horário para a sua participação presencial na própria universidade. Na situação de teste, era solicitado que usasse o aplicativo empregando a técnica de pensar em voz alta (Think aloud). No fim da experiência, era realizada uma entrevista com as mesmas questões da pesquisa de opinião respondida pelo grupo 1 .

Adicionalmente, a validação foi realizada através da integração do aplicativo com o Facebook (2017) e o Google Analytics (2017). Todas as ações feitas por cada um dos 
VI Congresso Brasileiro de Informática na Educação (CBIE 2017)

Anais dos Workshops do VI Congresso Brasileiro de Informática na Educação (WCBIE 2017)

usuários foram registradas de forma individual no Google Analytics, identificando-se o acesso pelo nome do usuário fornecido a partir da integração com o Facebook.

Os dados levantados permitiram identificar pontos específicos em que o usuário encontrou dificuldade para realizar as tarefas no aplicativo, aspectos que atraíram o seu interesse, problemas de usabilidade e sugestões de melhorias.

\section{Apresentação do Software}

Ao acessar o aplicativo, o usuário acessa a tela de login com Facebook e insere as suas informações de acesso. Caso as informações estejam equivocadas, ele visualiza uma mensagem de erro e precisa realizar o login novamente. Caso as informações estejam corretas, ele acessa a tela de módulos, conforme apresentado na Figura 1:

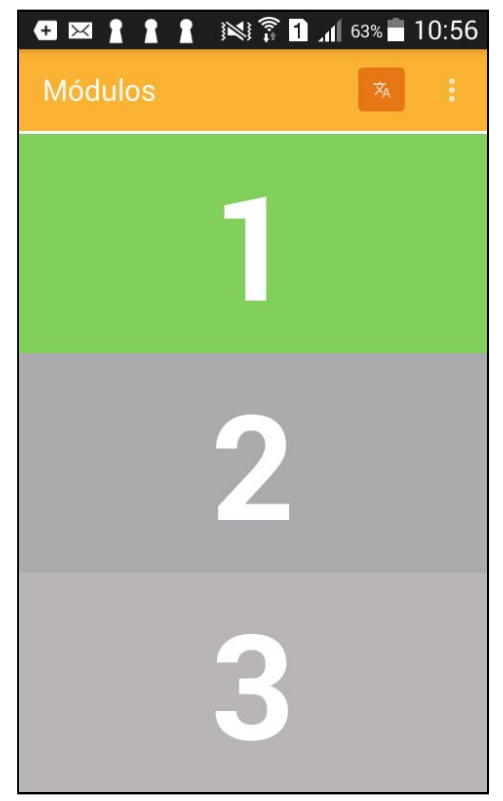

Figura 1. Representação da tela de módulos do Vecindario

Ao selecionar o módulo 1, o usuário visualiza a apresentação que contextualiza a presença de estudantes hispanofalantes na Unicamp e mostra a proximidade da língua espanhola ao cotidiano do universitário brasileiro. A Figura 2 ilustra as telas deste módulo: 
VI Congresso Brasileiro de Informática na Educação (CBIE 2017)

Anais dos Workshops do VI Congresso Brasileiro de Informática na Educação (WCBIE 2017)

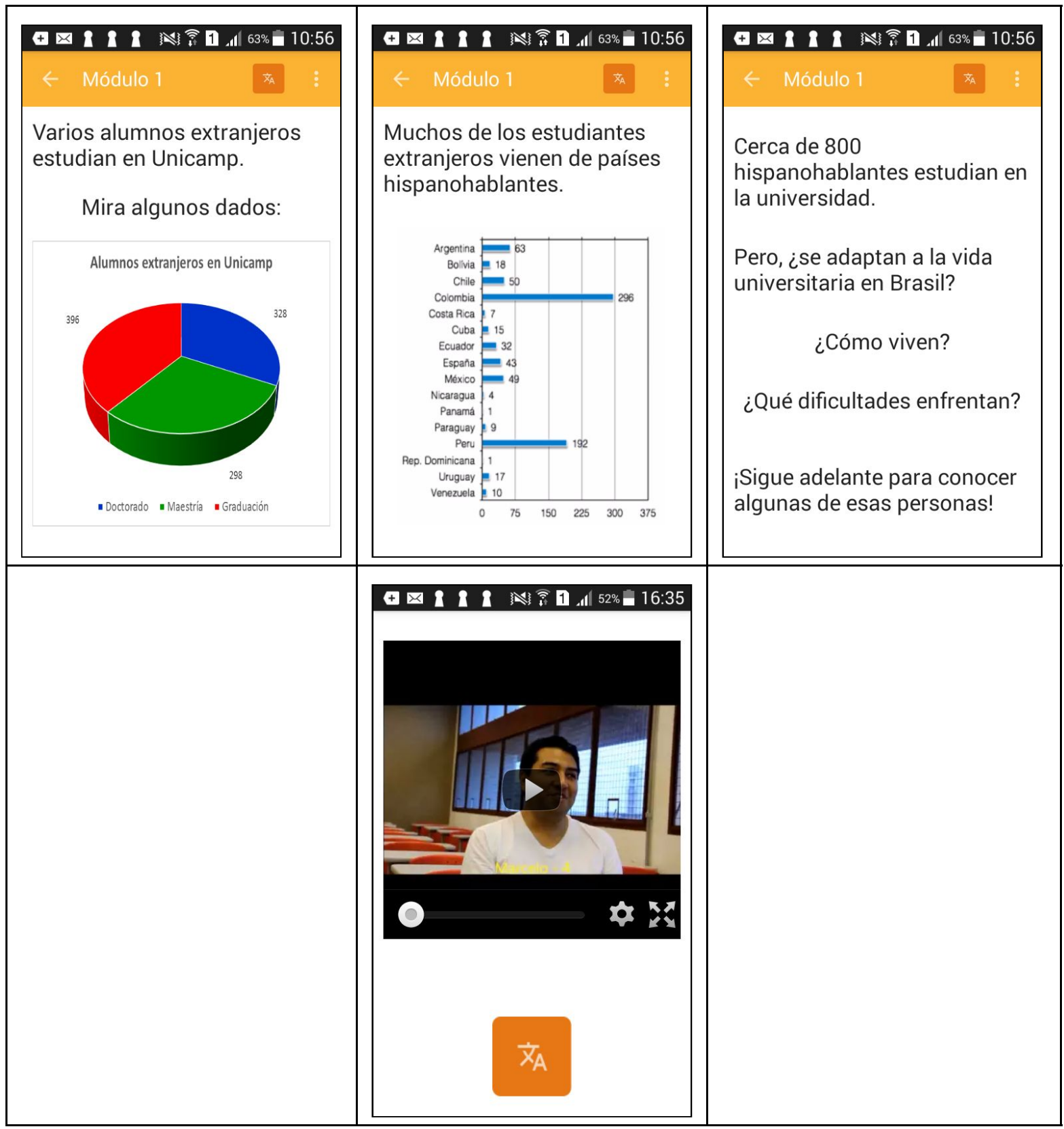

Figura 2. Exemplo das telas do módulo 1 do Vecindario

Após acompanhar todas as telas da apresentação, o usuário é encaminhado para a tela com o menu de tópicos, conforme ilustrado na Figura 3: 
VI Congresso Brasileiro de Informática na Educação (CBIE 2017)

Anais dos Workshops do VI Congresso Brasileiro de Informática na Educação (WCBIE 2017)

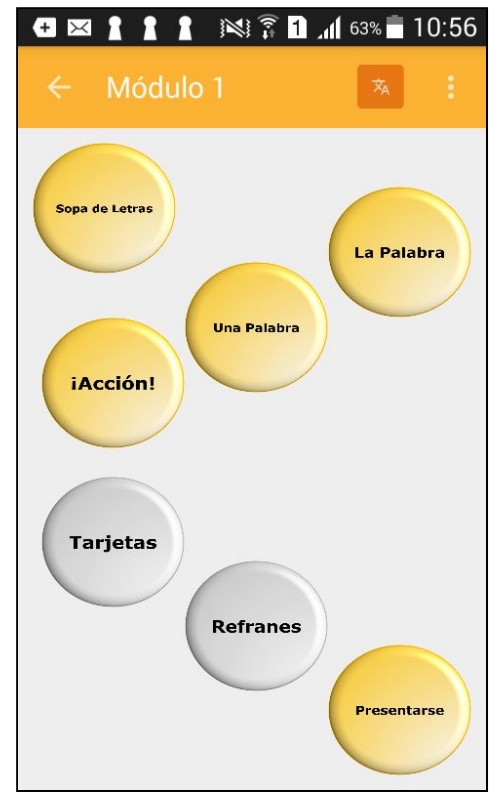

Figura 3. Tela com o menu de tópicos do módulo 1

Nessa tela, é possível escolher qual tópico se deseja realizar. No tópico Sopa de Letras, por exemplo, é introduzido um trecho da narrativa apresentada no aplicativo, cujo protagonista é o personagem brasileiro fictício José. Considerando que o contexto apresentado nos vídeos, de estudantes estrangeiros que vêm realizar estudos na Unicamp, pode ser similar ao que um estudante brasileiro enfrenta quando vai estudar no exterior, é apresentada uma narrativa, que vai sendo desenvolvida ao longo do curso, traçando um paralelo entre as situações vivenciadas pelos estudantes estrangeiros na Unicamp (relatadas nos vídeos) e o personagem brasileiro que vai estudar no exterior (relatado em quadrinhos com imagem e texto). Essa narrativa busca despertar empatia no participante pela situação vivenciada pelos colegas estrangeiros e aumentar a motivação pelos estudos da língua, ao se projetar em uma possível situação de estudo em um país de língua espanhola. O texto de apresentação do personagem José salienta a diferença de pronúncia do seu nome em português e espanhol.

$\mathrm{Na}$ tela seguinte, conforme ilustrado na Figura 4, são apresentadas expressões em uma nuvem de palavras, que devem ser tocadas alternadamente. Cada palavra dá acesso a uma nova tela com as seguintes informações: grafia e áudio da palavra selecionada (com a sua pronúncia em espanhol); explicação das diferenças e semelhanças fonéticas entre tal letra e a sua correspondente em português; e outros exemplos de palavras com a mesma letra, acompanhados de áudio com a pronúncia. Essa atividade é interativa, mas não será realizada uma avaliação de desempenho, já que a intenção é despertar o interesse e a motivação do participante. 
VI Congresso Brasileiro de Informática na Educação (CBIE 2017)

Anais dos Workshops do VI Congresso Brasileiro de Informática na Educação (WCBIE 2017)

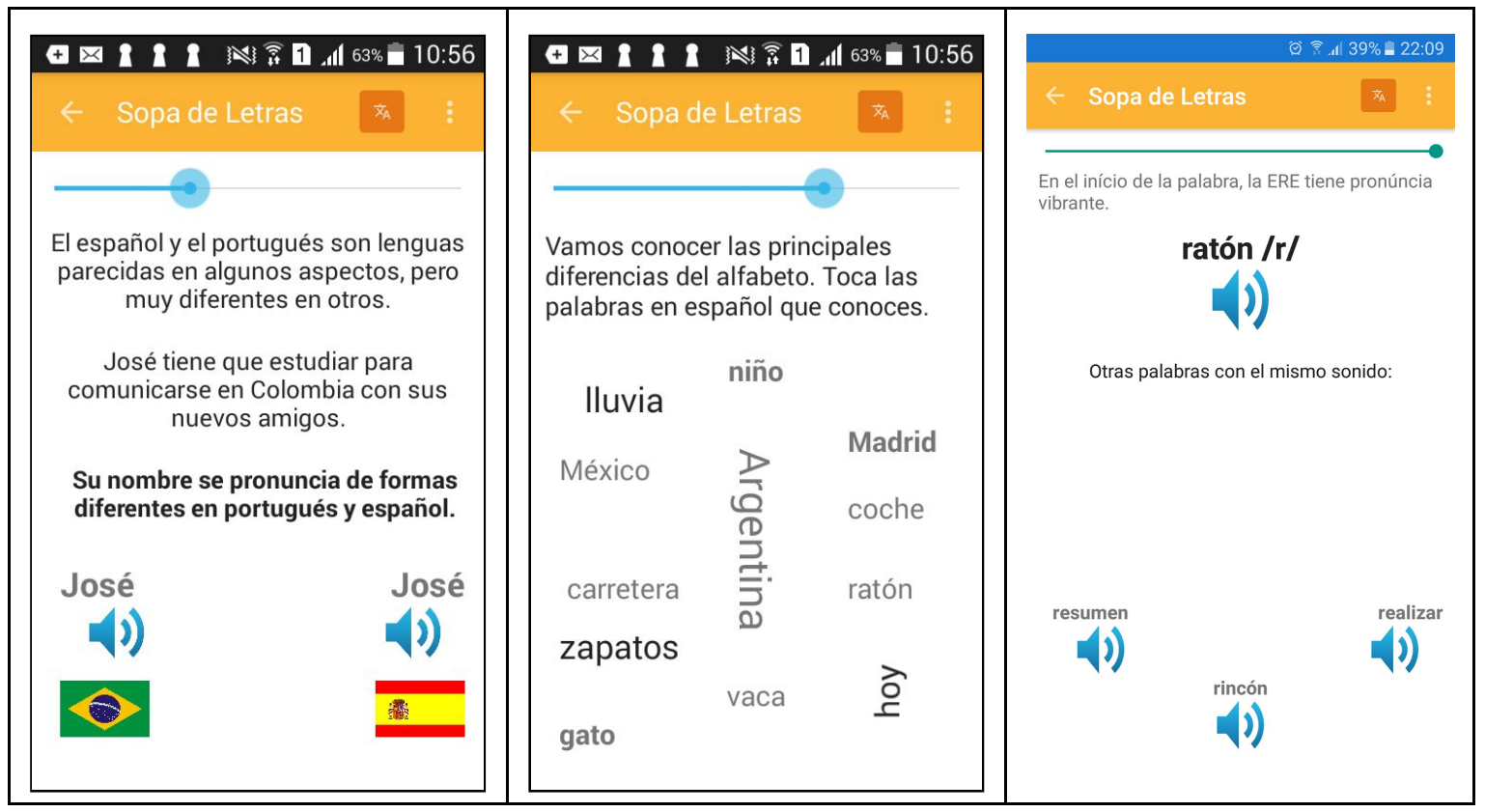

Figura 4. Telas do tópico Sopa de Letras

Por sua vez, no tópico Presentarse, o usuário deve colocar seus novos conhecimentos em prática em uma situação real de uso da língua espanhola. Primeiramente, é apresentado um áudio com uma breve explicação das formas de apresentação e saudação em situações informais de comunicação. A seguir, o participante é convidado a gravar um áudio com a sua própria apresentação pessoal utilizando o gravador disponibilizado na tela do aplicativo. Uma vez que o participante grave o áudio, este será enviado para um banco de dados do aplicativo ${ }^{1}$. O docente poderá analisar, avaliar e enviar um feedback para o participante. Os demais participantes do grupo poderão acessar o áudio e deixar um comentário para o colega que o gravou. A Figura 5, a seguir, ilustra as telas deste tópico:

\footnotetext{
${ }^{1}$ Esse recurso foi projetado mas ainda não está disponível. Provisoriamente, foi utilizado o Whatsapp como recurso para envio de áudio do aluno para o professor.
} 
VI Congresso Brasileiro de Informática na Educação (CBIE 2017)

Anais dos Workshops do VI Congresso Brasileiro de Informática na Educação (WCBIE 2017)

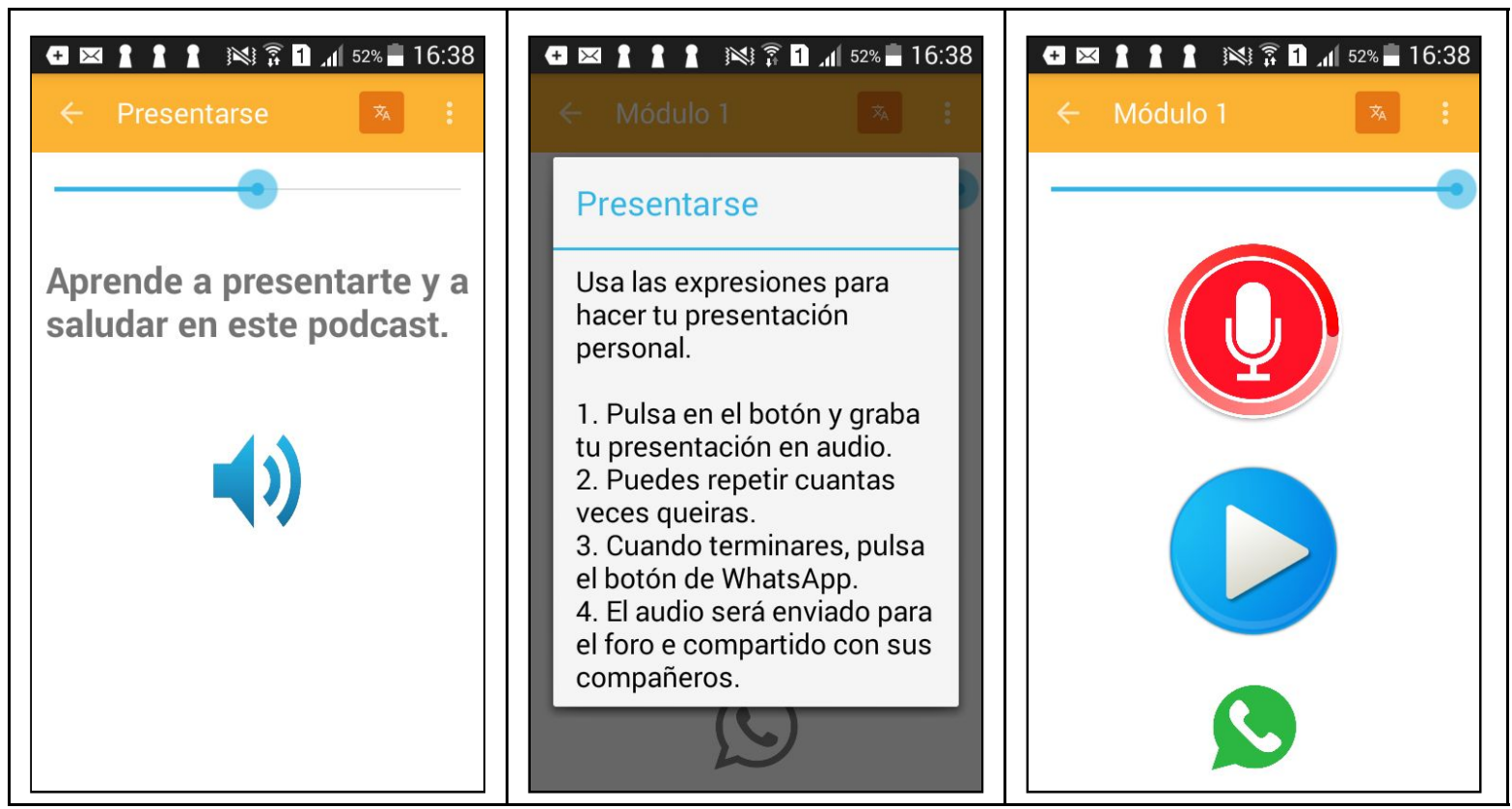

Figura 5. Telas do tópico Presentarse

O aplicativo Vecindario encontra-se disponível para download no seguinte link: https://play.google.com/store/apps/details?id=br.unicamp.Vecindario

\section{Considerações finais}

A experimentação do protótipo com os voluntários que participaram do projeto demonstrou que o aplicativo tem grande potencial para auxiliar jovens brasileiros no aprendizado da língua espanhola. Conforme ANDRADE (2017) em tese defendida a respeito da construção do aplicativo Vecindario, as características pedagógicas que embasam o design das atividades - como a aprendizagem situada, que explora o contexto de comunicação do aluno, bem como a multimodalidade, que integra diferentes modos de sentidos semióticos - levaram os voluntários participantes a um forte engajamento nas tarefas e absorção dos conhecimentos apresentados no Módulo 1.

Em termos gerais, os resultados da experiência indicam que o seu uso como ferramenta de estudo individual ou integrado a propostas de ensino presencial, favorece a aquisição da língua espanhola.

A validação com voluntários permitiu, também, identificar melhorias para aperfeiçoar o aplicativo e torná-lo mais eficiente no ensino da língua espanhola, como a implementação de ferramentas de gamificação, recursos de colaboração entre usuários e de feedback do professor.

Em trabalhos futuros, o grupo de pesquisadores responsável pelo desenvolvimento do aplicativo Vecindario, tem a intenção de seguir com o desenvolvimento do aplicativo, deixando as atividades mais robustas e sofisticadas e ampliando o acesso a um número maior de alunos universitários brasileiros. 
VI Congresso Brasileiro de Informática na Educação (CBIE 2017)

Anais dos Workshops do VI Congresso Brasileiro de Informática na Educação (WCBIE 2017)

\section{Agradecimentos}

Esta pesquisa foi parcialmente apoiada pela Fundação de Amparo à Pesquisa do Estado de São Paulo (FAPESP), processo no 2014/07502-4. Os autores agradecem o apoio da CAPES, CNPQ, Unicamp, FAPESP e SENAI/SP.

\section{Referências}

Andrade, I. R. (2017). “Aprendizagem de língua assistida por dispositivos móveis (ALADIM): uma proposta alternativa para o ensino da língua espanhola". Tese (Doutorado em Linguística Aplicada). Campinas-SP: Universidade Estadual de Campinas. $341 \mathrm{p}$.

Bitbucket. (2017) “Bitbucket”. Disponível em: <https://bitbucket.org/>. Acesso em: 21 mar.2017.

Facebook. (2017) "Facebook". Disponível em: <www.facebook.com> Acesso em: 21 mar. 2017.

Google Analytics (2017) "Google Analytics". Disponível em: <https://www.google.com/analytics> Acesso em: 29 jun. 2017

GIT. (2017) “Git: fast - version - control”. Disponível em: <https://git-scm.com/>. Acesso em: 21 mar. 2017.

Sourcetree. (2017) "Sourcetree". Disponível em: <https://www.sourcetreeapp.com/>. Acesso em: 21 mar. 2017.

Vecindario. (2017) "Projeto Vecindario". Disponível em: $<$ https://sites.google.com/site/projetoVecindario/>. Acesso em 05 jan. 2017.

Vecindario. (2017) "Aplicativo Vecindario". Disponível em: $<$ https://play.google.com/store/apps/details?id=br.unicamp.Vecindario $>$. Acesso em 03 fev. 2017.

Youtube. (2017) "Youtube". Disponível em: <www.youtube.com> Acesso em: 21 mar. 2017.

Whatsapp. (2017) "Whatsapp". Disponível em: <www.whatsapp.com> Acesso em: 21 mar. 2017. 